\begin{tabular}{|c|c|c|}
\hline \multirow{3}{*}{$\begin{array}{r}\text { Case Reports in } \\
\text { Gastroenterology }\end{array}$} & \multirow{2}{*}{\multicolumn{2}{|c|}{ Case Rep Gastroenterol 2014;8:304-309 }} \\
\hline & & \\
\hline & $\begin{array}{l}\text { DOI: 10.1159/000368114 } \\
\text { Published online: October 7, } 2014\end{array}$ & $\begin{array}{l}\text { ○ } 2014 \text { S. Karger AG, Basel } \\
\text { 1662-0631/14/0083-0304\$39.50/0 } \\
\text { www.karger.com/crg }\end{array}$ \\
\hline & \multicolumn{2}{|c|}{$\begin{array}{l}\text { This is an Open Access article licensed under the terms of the Creative Commons } \\
\text { Attribution-NonCommercial } 3.0 \text { Unported license (CC BY-NC) (www.karger.com/OA } \\
\text { license), applicable to the online version of the article only. Distribution permitted for non } \\
\text { commercial purposes only. }\end{array}$} \\
\hline
\end{tabular}
commercial purposes only.

\title{
Repeated Negative Biopsies in Isolated High-Grade Cystic Duct Dysplasia with Progression to Adenocarcinoma
}

\author{
Benjamin Sunkel-Laing ${ }^{a} \quad$ Abdul Kalam $^{a} \quad$ Ian Renfrew $^{b} \quad$ Lisa Mears $^{c}$ \\ Hemant M. Kocher ${ }^{\mathrm{a}}$ \\ Departments of ${ }^{\mathrm{a}}$ Hepatobiliary Surgery, ${ }^{\mathrm{b}}$ Interventional Radiology and ${ }^{\mathrm{C}}$ Pathology, \\ Barts and the London HPB Centre, The Royal London Hospital, Barts Health NHS Trust, \\ London, UK
}

\section{Key Words}

Cystic duct dysplasia $\cdot$ Adenocarcinoma $\cdot$ Cholangiocarcinoma

\begin{abstract}
Cystic and bile duct dysplasia is a rare histological finding, especially when found in the absence of an underlying malignancy. We report a patient who presented with jaundice and weight loss. Clinical and cytological evidence suggested a diagnosis of cholangiocarcinoma and the patient underwent a pancreatico-duodenectomy. Histopathological examination suggested a diagnosis of two foci of biliary dysplasia: cystic duct and lower common bile duct. Fifteen months later, the patient re-presented with signs of obstructive jaundice and biliary sepsis. Although CT scan revealed images highly indicative of metastatic disease, repeated biopsies failed to confirm this. Eventually a liver biopsy did reveal moderately differentiated adenocarcinoma, however oncological interventional was no longer appropriate and the patient was managed palliatively. This case report focuses on the current understanding of progression of biliary dysplasia.

(c) 2014 S. Karger AG, Basel
\end{abstract}

\section{Introduction}

Dysplasia is defined as an abnormality of cellular growth and development. An increase in cellular proliferation is associated with a reduced rate of apoptosis, while morphological features include hyperchromasia and pleomorphism. Dysplasia is classified histopathologi-

Centre for Tumour Biology, Barts Cancer Institute - a CRUK Centre of Excellence

Charterhouse Square, London EC1M 6BQ (UK)

E-Mail h.kocher@qmul.ac.uk 
Sunkel-Laing et al.: Repeated Negative Biopsies in Isolated High-Grade Cystic Duct

cally as either low- or high-grade according to the degree of cytological abnormalities and cellular pleomorphism [1]. As dysplastic cells do not invade the basement membrane, the term 'in situ neoplasia' is often used synonymously and is considered a pre-cancerous state.

In general, dysplasia is typically detected incidentally or as part of a screening investigation. With regard to ductal dysplasia, abnormalities, whether they be clinical, biochemical or radiological, will only be detectable if the lesion begins to occlude the lumen of the duct and therefore disrupt the normal function. In the context of the biliary ducts, disruption of normal luminal flow of bile can lead to obstructive jaundice [2].

Bile ductal dysplasia may represent a risk factor for the development of an invasive neoplasm at the same site. In this case, early detection of dysplastic cells at the duct margins, for example following a routine cholecystectomy, would allow more radical surgery to be performed early. This could, in theory, prevent the future development of an invasive carcinoma. Secondly, ductal dysplasia may be a risk factor for the development of malignancy at another site within the ductal tree, suggesting predisposition to neoplastic transformation as a field event. Lastly, and more commonly, ductal dysplasia is seen as a local extension of an existing invasive cancer. Observational studies have shown that high-grade cystic duct dysplasia is present at the margins of resected cholangiocarcinomas in up to $13 \%$ of cases [3]. Importantly, however, this appears to have no effect on overall survival, although there are higher rates of recurrence in long-term survivors.

\section{Case Report}

A 67-year-old gentleman was referred to the hepatobiliary surgical team after presenting to his general practitioner with features of obstructive jaundice-associated anorexia and weight loss of approximately $10 \mathrm{~kg}$ over a period of several months. Initial blood tests revealed a picture indicative of biliary obstruction: a raised serum bilirubin of $93 \mu \mathrm{mol} / \mathrm{l}$, a serum aspartate aminotransferase (AST) of $50 \mathrm{IU} / \mathrm{l}$ and a serum alkaline phosphatase (ALP) of $454 \mathrm{IU} / \mathrm{l}$. An ultrasound scan confirmed biliary obstruction characterised further by a CT scan as an intraluminal filling defect within the mid common bile duct (fig. 1a). Cellular brushings obtained during endoscopic retrograde cholangiopancreatography and biliary stenting demonstrated high-grade dysplastic cells but no evidence of invasive malignancy. Following a multi-disciplinary team meeting a provisional diagnosis of cholangiocarcinoma was made and the patient underwent pylorus-preserving pancreatoduodenectomy with Roux-en-Y reconstruction, pancreatojejunostomy, hepaticojejunostomy and gastrojejunostomy. Histological examination of the surgical specimen however did not reveal invasive malignancy but rather two foci of high-grade biliary dysplasia in the cystic duct and in the intrapancreatic segment of the common bile duct (fig. 1b). The post-operative period was complicated by a low-volume pancreatic leak which led to sepsis. The patient's blood results were as follows: a haemoglobin (Hb) level of $8.5 \mathrm{~g} / \mathrm{dl}$, a white cell count of $21.3 \times 10^{9} / \mathrm{l}$, a neutrophil count of $18.1 \times 10^{9} / \mathrm{l}$ and a platelet count of $293 \times 10^{9} / \mathrm{l}$. The patient had a bilirubin of $31 \mu \mathrm{mol} / \mathrm{l}$, an AST of $45 \mathrm{IU} / \mathrm{l}$ and an ALP of $63 \mathrm{IU} / \mathrm{l}$. C-reactive protein was 73 $\mathrm{mg} / \mathrm{l}$. The patient was managed conservatively with pleural and peritoneal drain placement percutaneously. Gastroparesis required the placement of a nasojejunal tube for feeding. These post-operative complications necessitated an in-patient stay of nearly 3 weeks. The patient was discharged with a normal full blood count and normalising liver function tests.

One week post-discharge the patient presented to the emergency department with haematemesis and collapse. On examination he was haemodynamically unstable with a $\mathrm{Hb}$ level of $5 \mathrm{~g} / \mathrm{dl}$ and platelets of $113 \times 10^{9} / \mathrm{l}$. He was transfused with packed red blood cells, 
Sunkel-Laing et al.: Repeated Negative Biopsies in Isolated High-Grade Cystic Duct

platelets and coagulation products and managed on the intensive care unit. Angiogram revealed a gastro-duodenal artery stump haemorrhage, which was treated with a covered stent over the origin of the gastro-duodenal artery (fig. 1c). Subsequently, for the first time, the patient manifested with bile leak from the old drain site. This was treated with a retrievable covered stent across the hepaticojejunostomy under percutaneous transhepatic cholangiography (fig. 1d), CT-guided drainage of the collection and broad-spectrum antibiotics. Enterococcus faecalis was managed with appropriate antibiotics. The patient was fit for discharge 4 weeks later. He did not undergo surveillance or chemotherapy as no invasive cancer was diagnosed.

After an uneventful and complication-free period of 14 months, the patient presented to the emergency department with jaundice and biliary sepsis. Liver function tests on admission showed a bilirubin of $54 \mu \mathrm{mol} / \mathrm{l}$, an AST of $52 \mathrm{IU} / \mathrm{l}$ and an ALP of $320 \mathrm{IU} / \mathrm{l}$. C-reactive protein was $91 \mathrm{mg} / \mathrm{l}$. A CT scan revealed a large $9-\mathrm{cm}$ central soft tissue mass in segment V/VIII of the liver, at the confluence of the right and left biliary trees, and multiple smaller liver lesions, an appearance highly suggestive of metastatic disease (fig. 2a). However, no evidence of malignancy was obtained from a targeted ultrasound-guided liver biopsy and the patient was therefore treated with antibiotics, percutaneous transhepatic cholangiogram and biliary drains (fig. 2b, c). Repeat CT showed no change in appearance of the liver lesions, therefore ruling out abscess. After nearly 2 months following the previous biopsy, the patient attended electively for a check cholangiography, repeat biliary stenting and a repeat liver biopsy. This biopsy showed moderately differentiated adenocarcinoma, in keeping with a metastatic cholangiocarcinoma (fig. 2d). Re-assessment of pancreatico-duodenectomy specimen with multiple levels failed to reveal any focus of invasive cancer. On follow-up assessments the patient's liver function tests continued to deteriorate, with a bilirubin of $234 \mu \mathrm{mol} / \mathrm{l}$, an alanine aminotransferase of $80 \mathrm{IU} / \mathrm{l}$, an AST of $200 \mathrm{IU} / \mathrm{l}$, an ALP of $364 \mathrm{IU} / \mathrm{l}$ and a gamma-glutamyl transferase of $563 \mathrm{IU} / \mathrm{l}$. The patient was referred for palliative care as he was unfit for chemotherapy. He unfortunately died secondary to biliary sepsis several weeks later.

\section{Discussion}

Considering that a tissue diagnosis of malignancy was eventually made, it may be worth delineating the potential relevance of the original presence of cystic duct dysplasia. The cystic duct dysplasia may have either represented a pathological state from which the eventual adenocarcinoma directly originated or one which shared common risk factors, such that the presence of dysplastic cells forecasts the development of malignant cells at an independent site. As the pylorus-preserving pancreatoduodenectomy specimen showed no malignant cells, it is unlikely that the cystic duct dysplasia represented a local extension of an existing carcinoma.

There is very little literature on the prevalence, aetiology or management of cystic duct dysplasia and the associated incidence of cholangiocarcinoma. Cholangiocarcinoma is a rare diagnosis [4]. Bile duct carcinoma is frequently associated with dysplasia and is multifocal in $10 \%$ of cases [5]. Cystic duct dysplasia may therefore be associated with an underlying bile duct carcinoma. To date, only one case series has been published interrogating the presence of cystic duct dysplasia in the absence of existing carcinoma [6]. This study identified only 4 patients with cystic duct dysplasia from a total of 193 who underwent cholecystectomies with cancer-free specimens. A recent study from our institution demonstrated that up to $2.8 \%$ of patients might have incidental gall bladder dysplasia or carcinoma [7]. 
Sunkel-Laing et al.: Repeated Negative Biopsies in Isolated High-Grade Cystic Duct Dysplasia with Progression to Adenocarcinoma

The risk factors for the development of cystic duct dysplasia remain incompletely understood much the same as invasive cholangiocarcinomas. Several studies have suggested that hepatitis $\mathrm{C}$ virus and alcohol may represent aetiological factors [8]. We have suggested that gall bladder dysplasia is more common in older patients and those with Asian ethnicity [7]. Several potential disease markers have been investigated. For example, expression of the oncofetal protein IMP3 (insulin-like growth factor II mRNA-binding protein 3) was found to correlate with increased tumour aggressiveness and reduced overall survival [9].

The case presented above posed several dilemmas regarding management decisions, including management of complications post-pancreatico-duodenectomy and surveillance of patients with dysplasia. The authors suggest a tailored approach for each patient in the absence of any longitudinal case-control or cohort studies. Currently there is no evidence for chemotherapy for dysplasia in the absence of invasive malignancy.

Based on clinical experience and the few published reports available, cystic duct dysplasia is certainly a rare condition, but one that warrants further investigation. It is worth noting that, despite the progression of pathology demonstrated in the above case and although dysplasia is generally considered a precursor to malignancy, not all dysplastic lesions ultimately develop malignancy. A small minority may remain unchanged in size for years and yet others may even disappear [10]. The authors suggest that high-grade biliary dysplasia be put on a surveillance programme in much the same way as invasive cholangiocarcinoma. If all the clinical and radiological clues point towards malignancy, treatment such as chemotherapy should be initiated even if a histological diagnosis cannot be confirmed. A more conservative management could leave the patient at risk.

\section{Disclosure Statement}

The authors have no conflicts of interest.

\section{References}

1 Odze RD, Goldblum JR (eds): Surgical Pathology of the GI Tract, Liver, Biliary Tract, and Pancreas. Philadelphia, Elsevier Health Sciences, 2009, pp 853-857.

-2 Nakata T, Kobayashi A, Miwa S, et al: Clinical and pathological features of primary carcinoma of the cystic duct. J Hepatobiliary Pancreat Surg 2009;16:75-82.

-3 Wakai T, Shirai Y, Moroda T, et al: Impact of ductal resection margin status on long-term survival in patients undergoing resection for extrahepatic cholangiocarcinoma. Cancer 2005;103:1210-1216.

-4 Coupland VH, Kocher HM, Berry DP, et al: Incidence and survival for hepatic, pancreatic and biliary cancers in England between 1998 and 2007. Cancer Epidemiol 2012;36:207-214.

5 Sasaki R, Takeda Y, Funato 0, et al: Significance of ductal margin status in patients undergoing surgical resection for extrahepatic cholangiocarcinoma. World J Surg 2007;31:1788-1796.

6 Bickenbach KA, Shia J, Klimstra DS, et al: High-grade dysplasia of the cystic duct margin in the absence of malignancy after cholecystectomy. HPB (Oxford) 2011;13:865-868.

7 Solaini L, Sharma A, Watt J, et al: Predictive factors for incidental gallbladder dysplasia and carcinoma. J Surg Res 2014;189:17-21.

8 Torbenson M, Yeh MM, Abraham SC, et al: Bile duct dysplasia in the setting of chronic hepatitis C and alcohol cirrhosis. Am J Surg Pathol 2007;31:1410-1413.

-9 Riener MO, Fritzsche FR, Clavien PA, et al: IMP3 expression in lesions of the biliary tract: a marker for high-grade dysplasia and an independent prognostic factor in bile duct carcinomas. Hum Pathol 2009;40: 1377-1383.

10 Trimble CL, Piantadosi S, Gravitt P, et al: Spontaneous regression of high-grade cervical dysplasia: effects of human papillomavirus type and HLA phenotype. Clin Cancer Res 2005;11:4717-4723. 


\begin{tabular}{|c|c|c|}
\hline \multirow{3}{*}{$\begin{array}{r}\text { Case Reports in } \\
\text { Gastroenterology }\end{array}$} & \multirow{2}{*}{\multicolumn{2}{|c|}{ Case Rep Gastroenterol 2014;8:304-309 }} \\
\hline & & \\
\hline & DOI: $10.1159 / 000368114$ & $\begin{array}{l}\text { (c) } 2014 \text { S. Karger AG, Basel } \\
\text { www.karger.com/crg }\end{array}$ \\
\hline
\end{tabular}

Sunkel-Laing et al.: Repeated Negative Biopsies in Isolated High-Grade Cystic Duct Dysplasia with Progression to Adenocarcinoma
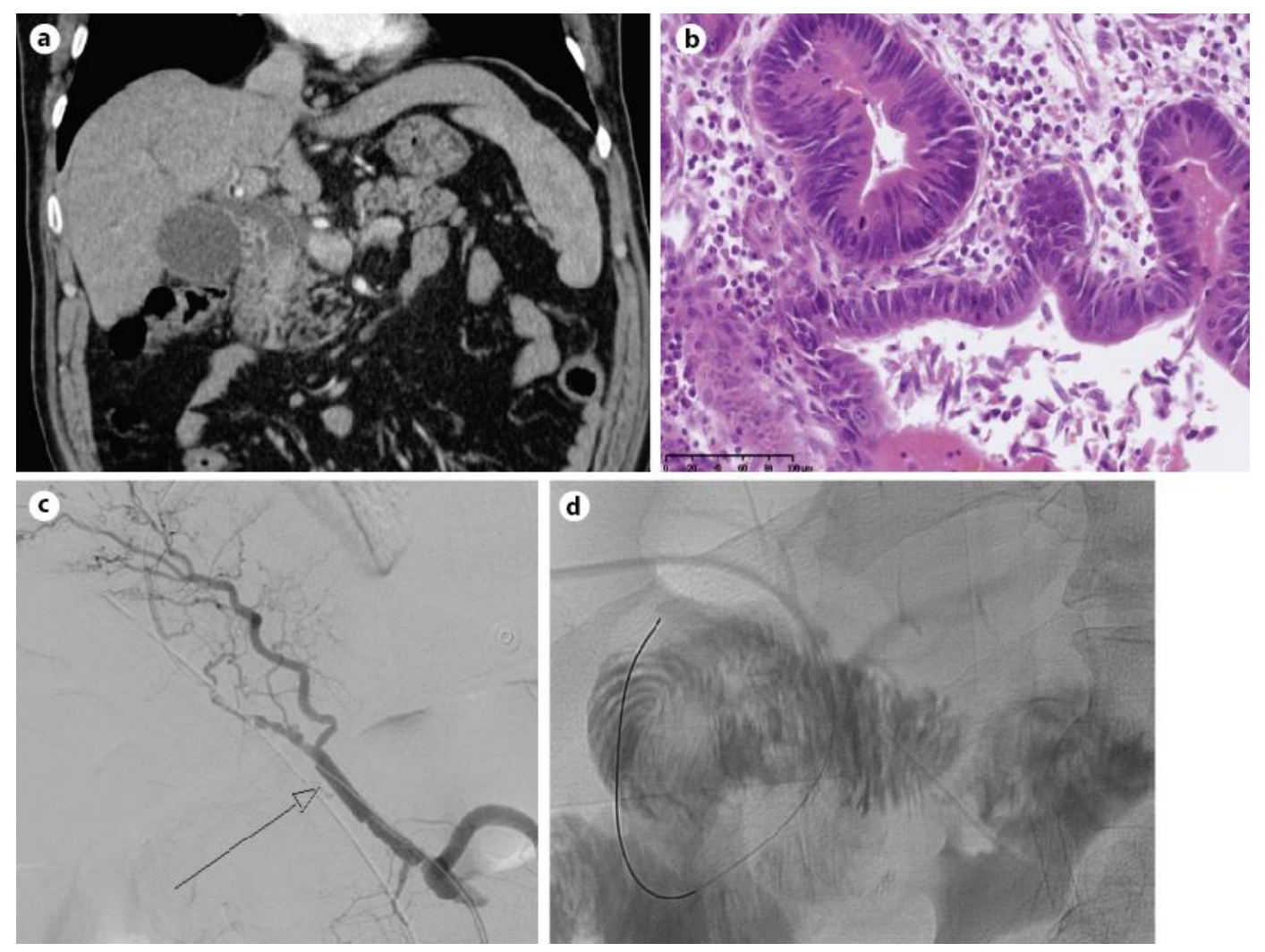

Fig. 1. Initial presentation and treatment with management of complications. 


\begin{tabular}{l|l}
\hline Case Rep Gastroenterol 2014;8:304-309 \\
\hline DOI: 10.1159/000368114 & $\begin{array}{l}\text { @ 2014 S. Karger AG, Basel } \\
\text { www.karger.com/crg }\end{array}$ \\
\hline
\end{tabular}

Sunkel-Laing et al:: Repeated Negative Biopsies in Isolated High-Grade Cystic Duct Dysplasia with Progression to Adenocarcinoma

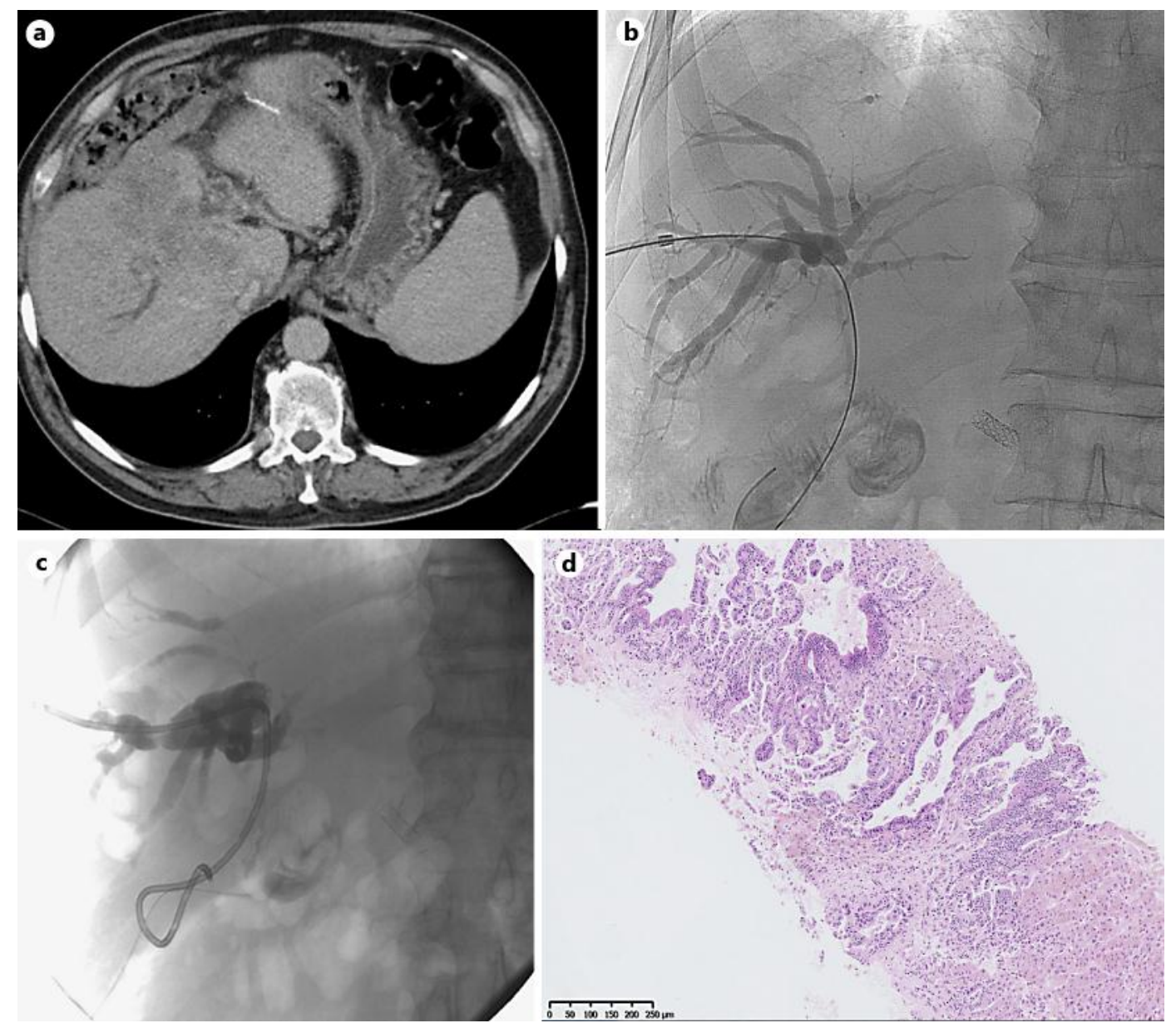

Fig. 2. Re-presentation with advanced cancer. 